\title{
Van Wyk-Grumbach syndrome and oligosyndactyly in a 6-year-old girl: a case report
}

\author{
Niranjalee Samanthika Egodawaththe ${ }^{1 *}$, Sumudu Nimali Seneviratne ${ }^{2}$, Suvini Gunasekara ${ }^{\text {, }}$ \\ Sathika Manori Amarasekara ${ }^{1}$ and Kumudu Weerasekara ${ }^{1}$
}

\begin{abstract}
Background: Van Wyk-Grumbach syndrome refers to the development of isosexual precocious pseudopuberty and multicystic enlarged ovaries in the presence of hypothyroidism and delayed bone age. It is a rare presentation of untreated hypothyroidism. The prepubertal response in Van Wyk-Grumbach syndrome is always isosexual and mediated by very high thyroid-stimulating hormone levels acting through the follicle-stimulating hormone receptors inducing a follicle-stimulating hormonal effect. Early recognition and thyroid hormone replacement can completely regress precocious puberty and ovarian enlargement, while improving the final height achievement. Oligosyndactly is a congenital bony abnormality and can manifest either as an isolated malformation or as a component of a syndromic diagnosis. However, development of hypothyroidism in children with this peculiar bony deformity has rarely been described in the medical literature, with the exception of Cenani-Lenz Syndactyly syndrome.
\end{abstract}

Case presentation: We report the case of a 6-year-old Sri Lankan girl who presented with a 2-day history of vaginal bleeding and exertional dyspnea. She had marked short stature (well below -3 standard deviations) with an upper segment to lower segment ratio of 1.47. This girl had isolated breast development of Tanner stage 2 . She was diagnosed to have acquired hypothyroidism secondary to autoimmune thyroiditis and also had macrocytic anemia, pericardial effusion, gonadotropin-releasing hormone-independent precocious puberty with radiological evidence of pubertal changes in the uterus, and multicystic ovaries. Interestingly, she also had post-axial oligosyndactyly in both feet and right-sided clubfoot. The diagnosis of Van Wyk-Grumbach syndrome was made based on the clinical and laboratory features. Her symptoms were successfully managed with L-thyroxine therapy.

Conclusions: Acquired hypothyroidism is a relatively common endocrine disorder among children and early recognition is important to prevent serious complications like Van Wyk-Grumbach syndrome. Sexual precocity with delayed bone age and stunting should direct our minds toward this unique diagnosis. It is always necessary to identify the other associated anomalies in addition to the primary diagnosis since these features may direct to a syndromic diagnosis.

Keywords: Van Wyk-Grumbach syndrome, Precocious puberty, Hypothyroidism, Oligosyndactyly

\footnotetext{
* Correspondence: samanthika41@gmail.com

${ }^{1}$ Lady Ridgeway Hospital for Children, Colombo, Sri Lanka

Full list of author information is available at the end of the article
}

C The Author(s). 2020 Open Access This article is licensed under a Creative Commons Attribution 4.0 International License, which permits use, sharing, adaptation, distribution and reproduction in any medium or format, as long as you give appropriate credit to the original author(s) and the source, provide a link to the Creative Commons licence, and indicate if changes were made. The images or other third party material in this article are included in the article's Creative Commons licence, unless indicated otherwise in a credit line to the material. If material is not included in the article's Creative Commons licence and your intended use is not permitted by statutory regulation or exceeds the permitted use, you will need to obtain permission directly from the copyright holder. To view a copy of this licence, visit http://creativecommons.org/licenses/by/4.0/ The Creative Commons Public Domain Dedication waiver (http://creativecommons.org/publicdomain/zero/1.0/) applies to the data made available in this article, unless otherwise stated in a credit line to the data. 


\section{Background}

Precocious puberty may be a rare presentation of untreated hypothyroidism, while delayed puberty is its norm [1]. Van Wyk-Grumbach syndrome (VWGS) refers to the development of isosexual precocious pseudopuberty and multicystic enlarged ovaries in the presence of hypothyroidism and delayed bone age [2]. The hormonal spectrum of these patients is characterized by elevated prolactin, estradiol, thyroid-stimulating hormone (TSH), together with decreased free thyroxine [3]. The prepubertal response in VWGS is always isosexual and mediated by very high TSH levels acting through the follicle-stimulating hormone (FSH) receptor inducing a follicle-stimulating hormonal effect [4]. Phenotypically, breast enlargement, multicystic ovaries, and menstrual bleeding are encountered in girls whereas boys only have testicular enlargement [3]. Early recognition and commencement of thyroid hormone replacement are the key steps in the management of patients with VWGS. These measures will resolve symptoms rapidly and improve the height achieved. In addition, reversal to the prepubertal state is typically seen following the appropriate treatment. Oligosyndactly is a congenital bony abnormality and can manifest either as an isolated malformation or as a component of a syndromic diagnosis. However, development of hypothyroidism in syndromic children with this peculiar bony deformity has rarely been described in the medical literature with the exception of the rare genetic disorder Cenani-Lenz Syndactyly (CLS) syndrome.

In this article, we report the clinical details of the case of a Sri Lankan girl who had typical features of VWGS and exhibited a successful recovery. The aim of this report is to highlight the devastating consequences of longstanding hypothyroidism and the importance of timely intervention to preserve the final height of the affected children as there can be diagnostic dilemma for this disease at the outset. Moreover, we review the literature to clarify whether there is an unusual association between VWGS and oligosyndactyly, which has not been described previously.

\section{Case presentation}

A 6-year-old girl from central Sri Lanka presented with a 2-day history of vaginal bleeding. There was no history of local trauma and other bleeding manifestations. She had recent onset exertional dyspnea. Her parents reported that the child was not performing well academically and was not interacting with her peers. There was no galactorrhea, headache, or visual disturbance. She was the second child born to healthy unrelated parents, with an uneventful birth and perinatal history. There was no family history of pubertal precocity or thyroid disease. A detailed dietary history included a 24-hour dietary recall and revealed that her diet was highly deficient in both quality and quantity and she had only received about $60 \%$ of the required calories. Our patient had been lost to follow-up at the routine field pediatric clinic when she was 3 years.

On examination, the child had disproportionate short stature for her age (height $84 \mathrm{~cm}$, well below -3 standard deviation score (SDS)) with an upper segment to lower segment ratio 1.47 (normal 1.1). Her weight was $13 \mathrm{~kg}$ (below the third centile) and her head circumference was $45 \mathrm{~cm}(<-3 S D S)$. She had post-axial oligosyndactyly in both feet and right-sided talipes deformity (Fig. 1).

She was lethargic and pale. There was no goiter. She had bradycardia with a pulse rate of 64 beats/minute. Her blood pressure was normal while her heart sounds were muffled. Her respiratory rate at rest was 16 cycles/ minute and oxygen saturation on air was $100 \%$. She had early breast development (Tanner stage 2), with no axillary or pubic hair. Abdominal, respiratory, and nervous system examinations were normal, except for slowrelaxing reflexes.

On investigation, her bone age was delayed (3 years), and laboratory test results (Table 1) were suggestive of autoimmune hypothyroidism, macrocytic anemia, and gonadotropin-releasing hormone (GnRH)-independent precocious puberty. An ultrasound scan of her pelvis showed an enlarged uterus with pubertal changes (size

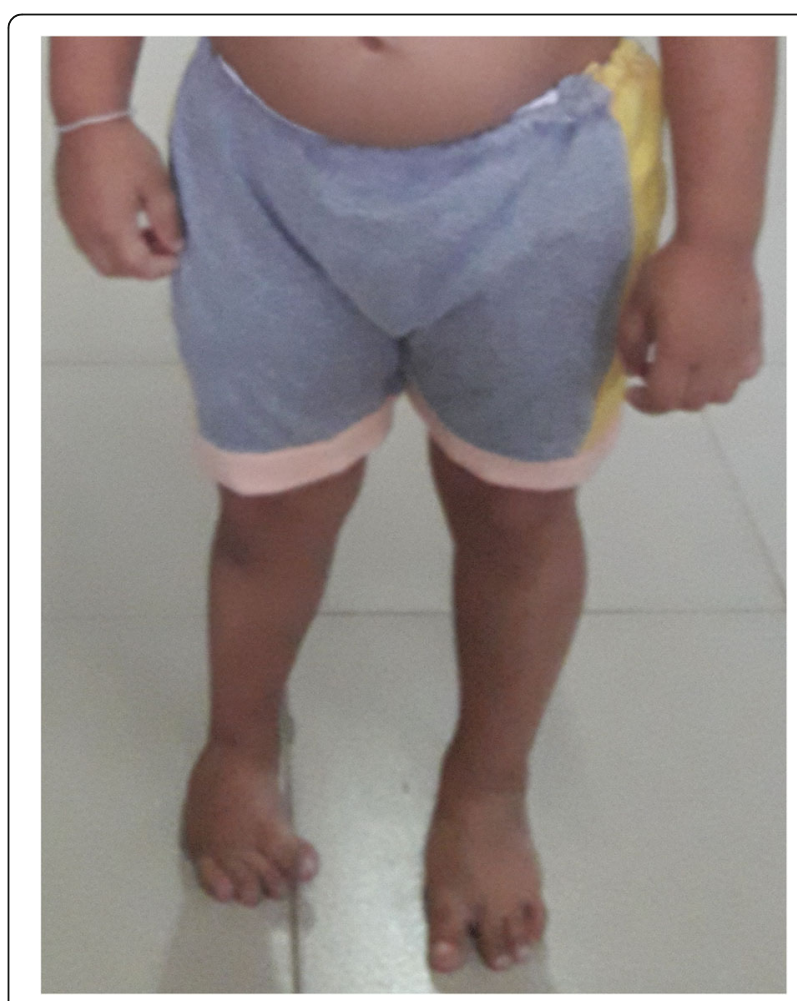

Fig. 1 Phenotypic appearance showing right-sided talipes deformity with bilateral post-axial oligosyndactyly 
Table 1 Blood test results on admission

\begin{tabular}{lll}
\hline Test & Initial results & Reference range \\
\hline Free thyroxine & $<5.15$ & $9-25 \mathrm{pmol} / \mathrm{L}$ \\
$\mathrm{TSH}$ & $>100$ & $0.7-4.61 \mathrm{mIU} / \mathrm{L}$ \\
$\mathrm{TPO}$ Ab titer & 495.64 & $<5.61 \mathrm{IU} / \mathrm{L}$ \\
$\mathrm{TG}$ Ab titer & 231.63 & $<4.11 \mathrm{IU} / \mathrm{L}$ \\
$\mathrm{LH}$ & $<0.07$ & $0.08-3.9 \mathrm{IU} / \mathrm{L}$ \\
FSH & 8.72 & $0.1-11.3 \mathrm{IU} / \mathrm{L}$ \\
Estradiol & 416 & $<59 \mathrm{pmol} / \mathrm{L}$ \\
Prolactin & 966 & $109-556 \mathrm{mIU} / \mathrm{L}$ \\
Hemoglobin & 9 & $11.5-14.5 \mathrm{~g} / \mathrm{dL}$ \\
Cortisol & 247 & $83-580 \mathrm{nmol} / \mathrm{L}$ \\
Mean corpuscular volume & 98 & $76-90 \mathrm{fL}$ \\
ESR & 10 & $<20$ \\
\hline
\end{tabular}

$E S R$ erythrocyte sedimentation rate, $L H$ luteinizing hormone, $T G A b$ thyroglobulin antibody, TPO Ab thyroid peroxidase antibody

$3.6 \mathrm{~cm} \times 1.9 \mathrm{~cm} \times 2.5 \mathrm{~cm}$, fundus: cervix ratio $3.6: 2.7$, endometrial thickness (ET) $4 \mathrm{~mm}$ ) (Fig. 2), and enlarged ovaries with multiple cysts (Fig. 3). She had an ultrasonically normal renal system. Thyroid ultrasonography had features consistent with thyroiditis, namely, a mildly enlarged gland with irregular echo patterns and high vacularization. Two-dimensional echocardiography revealed a moderate pericardial effusion, which had caused the recent-onset exertional dyspnea. An abnormally wide and deep sella turcica was seen on a lateral skull X-ray. Magnetic resonance imaging of her brain to evaluate the pituitary gland in detail was not done due to limited radiological facilities. There were no radiological bony abnormalities in her lower limbs apart from oligosyndactyly of the second and third toes bilaterally. A formal developmental assessment was performed by a child psychiatrist and found that her intelligence quotient (IQ) was normal. Audiological and visual assessment results were normal.

On the basis of the clinical and laboratory findings, she was diagnosed to have VWGS. She was initially commenced on a low dose of L-thyroxine at $5 \mu \mathrm{g} / \mathrm{kg} /$ day to avoid precipitating cardiac failure and the dose was gradually titrated up, in accordance with the clinical and biochemical parameters. The age-appropriate replacement dose was thereby achieved gradually. Before starting treatment, her serum cortisol level ( 8 am value) was analyzed and confirmed to be normal.

On follow-up, she exhibited marked improvement in clinical parameters. Her height increased by $6 \mathrm{~cm}$ over the first 3 months and another $5 \mathrm{~cm}$ over the subsequent 3 months, consistent with a height velocity surpassing the 97th percentile (Fig. 4). The echocardiogram done following the first month of thyroxine therapy revealed complete resolution of her pericardial effusion and she had recovered from the exertional dyspnea and bradycardia by 2 weeks after the treatment start. Her anemia was resolved following 1 month of thyroxine. Furthermore, her ovarian cysts disappeared and breast size regressed, and she did not experience further menstruation. She started to perform school activities enthusiastically and her social interactions were improved.

\section{Discussion and conclusions}

In 1960, Van Wyk and Grumbach first described this unusual clinical spectrum and it is now termed VWGS [2]. The incongruous combination of precocious puberty and delayed growth is characteristic of VWGS. The presence of short stature and delayed bone age and the lack of axillary and pubic hair development differentiates this condition from other causes of pubertal precocity $[1,5]$.

The etiology of hypothyroidism in VWGS is often lymphocytic thyroiditis, though it also has been reported

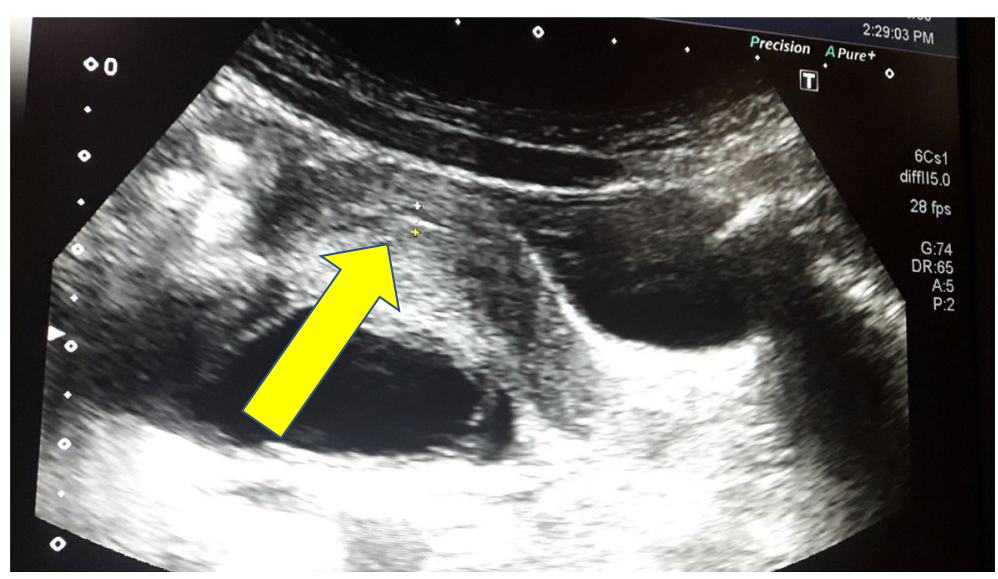

Fig. 2 Ultrasound scan image of enlarged uterus (yellow arrow) measuring $3.6 \mathrm{~cm} \times 1.9 \mathrm{~cm} \times 2.5 \mathrm{~cm}$ and endometrial thickness of $4 \mathrm{~mm}$ 


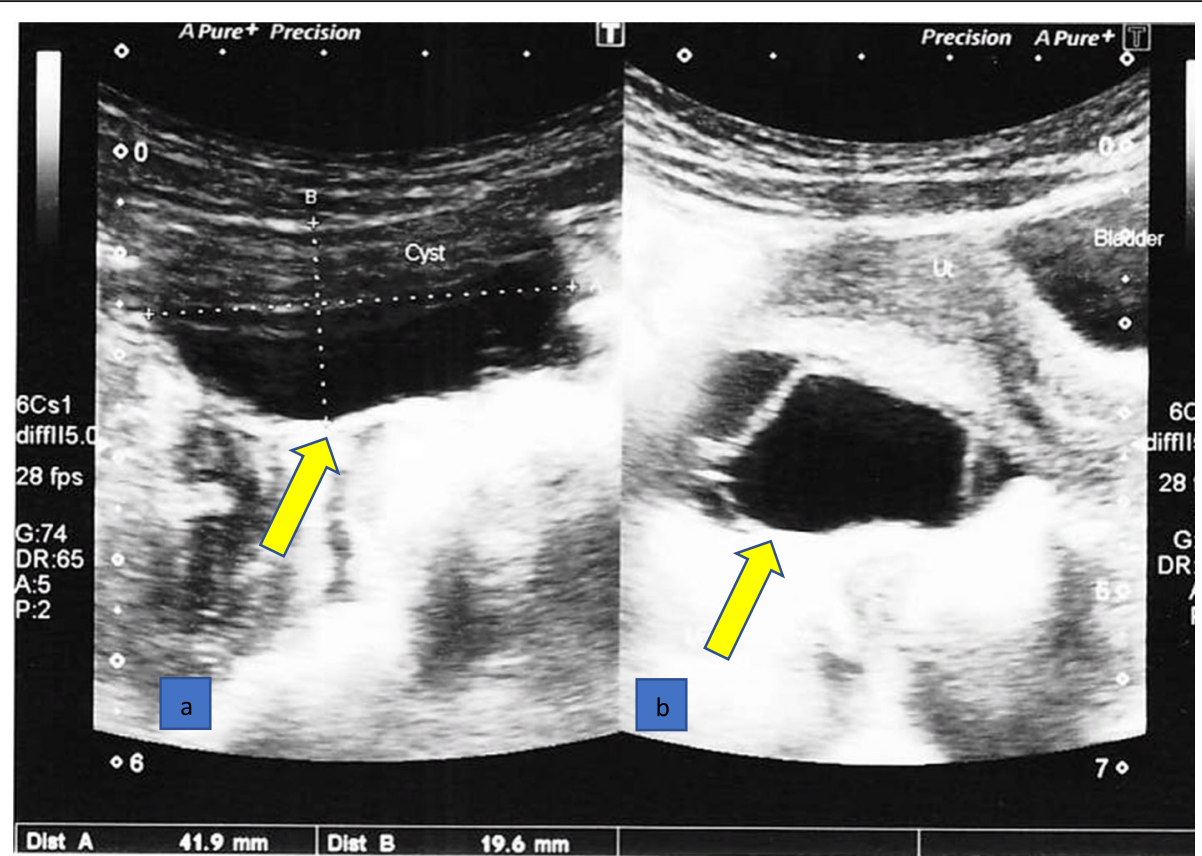

Fig. 3 Ultrasound scan image of a $3.3 \mathrm{~cm} \times 2.1 \mathrm{~cm} \times 2.5 \mathrm{~cm}$ sized complex cyst (yellow arrow) (a) and enlarged left ovary (yellow arrow) (b)

in association with unrecognized congenital hypothyroidism $[6,7]$. In this child, elevated thyroid autoantibodies and preserved IQ pointed to acquired autoimmune hypothyroidism, though it is relatively uncommon at such a young age [8].

The hormonal interaction involving the pathogenesis of VWGS is complex and speculated. The most acceptable theory is that the very high TSH level seen in profound hypothyroidism interacts with the FSH receptor. Gonadotropins as well as TSH are glycoproteins and all these hormones share the same $\alpha$-subunit, though the $\beta$-subunit is identical to each hormone. Anasti et al. have demonstrated the interaction of recombinant TSH with FSH receptor to stimulate adenylate cyclase activity and shown that recombinant TSH acted as a competitive inhibitor of FSH [3, 9]. Therefore, increased levels of TSH act through the FSH receptors ("specificity spillover") and induce FSH-like effects on the gonads, causing multicystic ovaries, uterine enlargement with bleeding and breast enlargement in girls [5, 7, 9-11]. In boys, this leads to macroorchidism without virilization [10]. In addition, persistently high thyrotropin-releasing hormone (TRH) stimulates FSH secretion. Patients with VWGS have a high or upper limit of the ageappropriate level of FSH and we noticed a high FSH level in our patient. Axillary and pubic hair growth does not occur, as there is no stimulation of adrenarche, which explains the absence of consonant pubertal development in VWGS.
The role of prolactin theory elaborates the discordance between FSH and luteinizing hormone (LH) in this syndrome [4, 5]. Hyperprolactinemia occurs due to unopposed secretion of prolactin due to elevated TRH and prolactin can increase the sensitivity of the ovaries to gonadotropins, while slowing down gonadotropin-releasing hormone $(\mathrm{GnRH})$ pulse frequency $[5,12]$. Interestingly, slow GnRH pulses suppress LH while producing FSH [13]. This causes an isolated FSH response as in our patient.

In 2011, Durbin and colleagues exemplified VWGS in a 12-year-old Caucasian girl who also had a pituitary macroadenoma and bilateral ovarian masses mimicking a tumor [14]. Another typical phenotype of VWGS with coexisting TSH-secreting adenoma and hyperprolactinemia was described in an 8-year-old girl with autoimmune thyroiditis by Baranowski and Högler in 2012 [5]. Pituitary hyperplasia occurs secondary to thyrotroph hyperplasia, which is induced by lack of thyroid hormonal feedback [15]. In the setting of untreated prolonged hypothyroidism, it can progress to pituitary adenoma. Our patient however, being a classic example of VWGS, only had pituitary hyperplasia, which was analyzed only with a lateral skull X-ray and revealed a wide and deep sella turcica.

Hypothyroid children have slow growth and increased weight. Moderate to severe obesity is not typical but commonly observed. However, decreased growth velocity is a constant finding unlike the weight. Our patient was not complying with this rule as she was markedly 


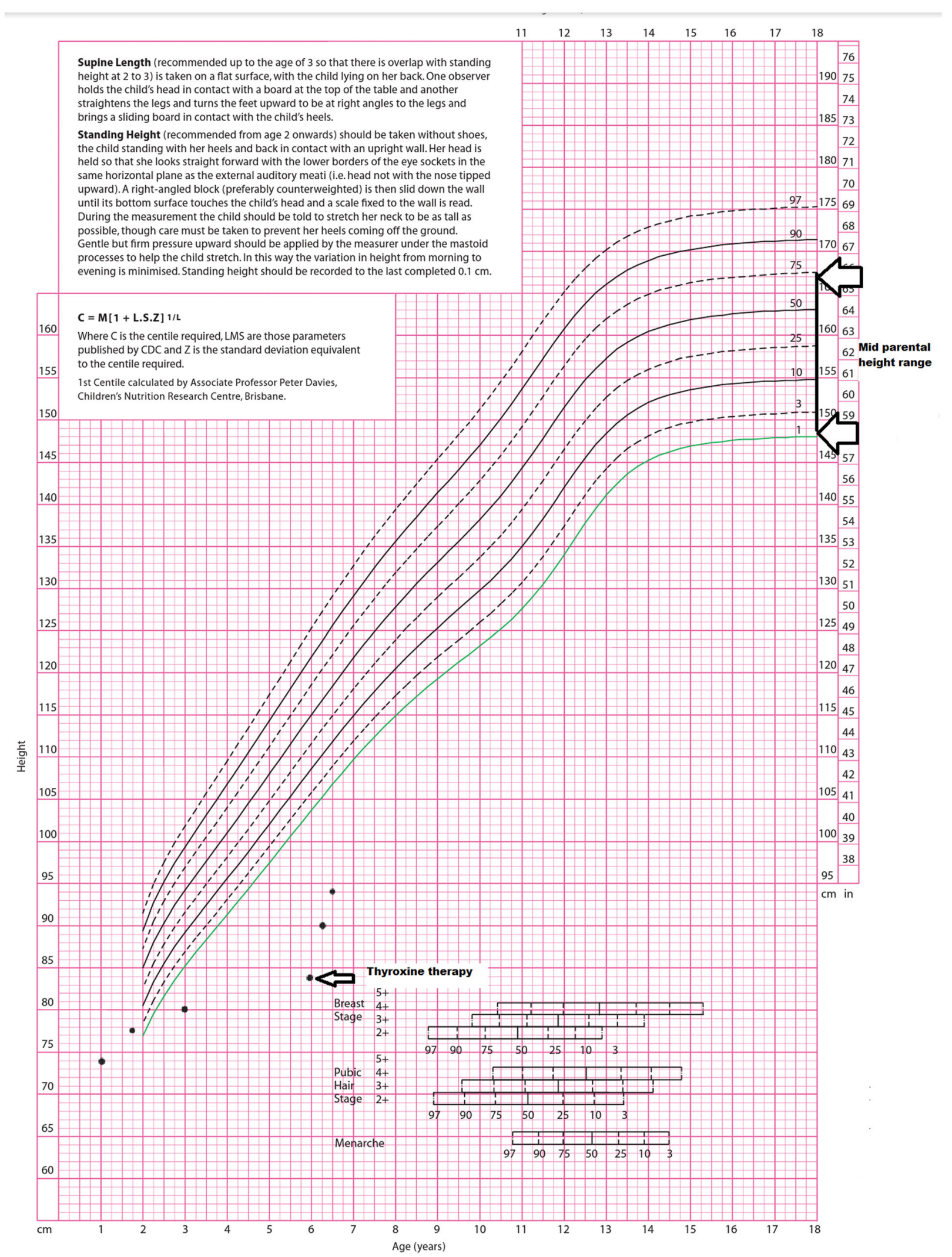

Fig. 4 Growth chart of our patient showing height well below 3 standard deviations at presentation and rapid acceleration following thyroid hormone replacement 
underweight, probably contributed to by the diet and possible underlying syndromic diagnosis.

Anemia and pericardial effusion are also well described in untreated hypothyroidism. Hypothyroidism may lead to macrocytic anemia due to suppressed bone marrow activity and erythropoietin secretion [8]. Reduced hematopoiesis in response to decreased metabolic demand, dietary deficiency, menorrhagia, and as a part of autoimmune cluster are other proposed mechanisms in the pathogenesis of anemia in hypothyroid patients [16]. Undetected and progressive hypothyroidism is associated with pericardial effusion and the attributed mechanisms are increase in capillary permeability causing protein-rich fluid extravasation into the pericardial sac, impaired lymphatic drainage, and increased salt and water retention [17].

In addition to the features consistent with VWGS, our patient had oligosyndactyly, right sided clubfoot, microcephaly, and severe growth failure, directing us to a possible syndromic diagnosis. Webbing of adjacent digits with or without bony fusion is termed as syndactyly and it is a common hereditary limb anomaly. It can occur either as an isolated malformation or as a component of a syndromic diagnosis and more than 300 associated syndromes have been identified [18]. Oligosyndactyly is one of the syndactyly phenotypes and it is a frequent feature in several syndromes, namely, CLS syndrome, fibular aplasia, tibial campomelia and oligosyndactyly (FATCO) syndrome, fibular hemimelia (FH), Cornelia de Lange (CdL) syndrome and chromosome 2q35 duplication syndrome. A comprehensive literature review revealed the rare association of syndactyly with hypothyroidism in CLS syndrome $[19,20]$. The genetic etiology of this is mapped to CLC1 locus on chromosome region 11p11.2-q13.1 and is thought to result from mutations in the LRP4 gene [20]. CLS syndrome is characterized by syndactyly and oligodactyly of fingers and toes, facial dysmorphism, renal anomalies and congenital hypothyroidism [20, 21]. However, the absence of dysmorphism and highly elevated thyroid autoantibody titers suggest the index case is a remote possibility of this diagnosis.

FATCO syndrome is a descriptive term to a collection of congenital limb deficiencies as described above. It has a great clinical variability and is sporadic in origin [22]. Patients with FATCO syndrome have normal IQ levels and not dimorphic or other malformations [22, 23]. FH is a spectrum of limb anomalies from mild fibular hypoplasia to fibular aplasia. It can occur sporadically or as a part of a syndrome and the anomalies are usually unilateral [22]. Associated components of $\mathrm{FH}$ are femur and tibia shortening, clubfoot, vulgus deformity, and anteroposterior instability of the knee and ankles [22, 24]. CdL syndrome is a dominantly inherited disorder and is characterized by facial dimorphism, limb anomalies, microcephaly, somatic growth, and cognitive retardation [25].
Chromosome 2q35 duplication syndrome also has autosomal dominant inheritance and the characteristic features are craniosynostosis and syndactyly [26]. However, occurrence of autoimmune thyroiditis has never been described in any of these syndromes.

Acquired hypothyroidism is a relatively common endocrine disorder among children, and early recognition is important to prevent serious complications like VWGS and pericardial effusions. Moreover, VWGS often comprises a diagnostic dilemma because of its rarity, and pubertal delay is the well-known consequence of prolonged untreated hypothyroidism. But its identification has paramount importance since the pubertal precocity is reversible and final height can be improved. Sexual precocity evident by isolated breast development in girls and testicular enlargement in boys occurring in a short-statured, obese child with delayed bone age would be the red flag signs of this rare diagnosis. In our patient's case, the presence of oligosyndactyly is likely to be an isolated finding since she had no characteristic syndromic features. We hope that this case history will encourage clinicians to manage hypothyroid patients optimally and promptly to avoid its complications and will persuade them to identify associated unusual features, which may direct into a syndromic diagnosis.

\section{Abbreviations \\ CdL: Cornelia de Lange; CLS: Cenani-Lenz Syndactyly; ESR: Erythrocyte sedimentation rate; ET: Endometrial thickness; FATCO: Fibular aplasia, tibial campomelia and oligosyndactyly; FH: Fibular hemimelia; FSH: Follicle- stimulating hormone; GnRH: Gonadotropin-releasing hormone; IQ: Intelligence quotient; LH : Luteinizing hormone; TG Ab: Thyroglobulin antibody; TPO Ab: Thyroid peroxidase antibody; TRH: Thyroid-releasing hormone; TSH: Thyroid-stimulating hormone; SDS: Standard deviation score; WWGS: Van Wyk-Grumbach syndrome}

\section{Acknowledgements}

We would like to thank our patient and her parents.

\section{Authors' contributions}

NSE cared for the patient, conceptualized and designed the case report and approved the final manuscript as submitted. SNS contributed to the initial draft, reviewed and revised the manuscript. SG and SMA cared for the patient and assisted in drafting the initial manuscript. KW contributed to the patient care supervision. All authors read and approved the final manuscript.

\section{Funding}

None.

Availability of data and materials

Not applicable.

Ethics approval and consent to participate Not applicable.

\section{Consent for publication}

Written informed consent was obtained from the patient's legal guardian for publication of this case report and any accompanying images. A copy of the written consent is available for review by the Editor-in-Chief of this journal.

Competing interests

The authors declare that they have no competing interests. 


\section{Author details}

'Lady Ridgeway Hospital for Children, Colombo, Sri Lanka. ${ }^{2}$ Department of Paediatrics, Faculty of Medicine, University of Colombo, Colombo, Sri Lanka.

Received: 27 June 2019 Accepted: 28 July 2020

Published online: 16 September 2020

\section{References}

1. Asirvatham AR, Mahadevan S, Balachandran K, Balasubramaniam SK. Van Wyk Grumbach syndrome: a case series and review of literature. Int J Sci Res. 2018;7(2):19-20.

2. Van Wyk JJ, Grumbach MM. Syndrome of precocious menstruation and galactorrhoea in juvenile hypothyroidism: an example of hormonal overlap in pituitary feedback. J Pediatr. 1960;57:416-35.

3. Zhang S, Yang J, Zheng R, Jiang L, Wei Y, Liu G. Van Wyk-Grumbach syndrome in a male pediatric patient: a rare case report and literature review. Exp Ther Med. 2017;13(3):1151-4.

4. Indumathi CK, Bantwal G, Patil M. Primary hypothyroidism with precious puberty and bilateral cystic ovaries. Indian J Pediatr. 2007;74:781-8.

5. Baranowski E, Högler W. An unusual presentation of acquired hypothyroidism: the Van Wyk-Grumbach syndrome. Eur J Endocrinol. 2012; 166:537-42.

6. Asami T, Kikuchi T, Kamimura S, Kinoshita S, Uchiyama M. Precocious puberty in a girl with congenital hypothyroidism receiving continuous Lthyroxine-replacement therapy. Pediatr Int. 2001;43(1):87-90.

7. Razi SM, Gupta AK, Gupta DC, Gutch M, Gupta KK, Usman SI. Van WykGrumbach syndrome with Kocher-Debré-Sémélaigne srndrome: case report of a rare association. Eur Thyroid J. 2017;6:47-51.

8. Marzuilla P, Grandone A, Perrotta, Ruggiero L, Capristo C, Luongo C, et al. Very early onset of autoimmune thyroiditis in a toddler with severe hypothyroidism presentation: a case report. Ital J Pediatr. 2016;42:61.

9. Anasti JN, Flack MR, Froehlich J, Nelson LM, Nisula BC. A potential novel mechanism for precocious puberty in juvenile hypothyroidism. J Clin Endocrinol Metab. 1995;80:276-9.

10. Sharma D, Dayal D, Gupta A, Saxena A. Premature menarche associated with primary hypothyroidism in a 5.5 year old girl. Case Rep Endocrinol. 2011;2011:678305

11. Wormsbecker A, Clarson C. Acquired primary hypothyroidism: vaginal bleeding in a quiet child. Can Med Assoc J. 2010;182960:588-99.

12. Cetinkaya S, Sagsak E, Erdeve S, Aycan Z, Keskin M. Premature menarche associated with Hashimoto thyroiditis at 2 years 9 months: case report. Thyroid Disorders Ther. 2014:3:159.

13. Thackray VG, Mellon PL, Coss D. Hormones in synergy: regulation of the pituitary gonadotropin genes. Mol Cell Endocrinol. 2010;314:192-203.

14. Durbin KL, Diaz-Montes T, Loveless MB. Van Wyk Grumbach Syndrome: an unusual case and review of literature. J Pediatr Adolesc Gynecol. 2011;24(4): e93-6.

15. Passeri E, Tufano A, Locatelli M, Lania AG, Ambrosi B, Corbetta S. Large pituitary hyperplasia in severe primary hypothyroidism. J Clin Endocrinol Metab. 2011;96(1):22-3.

16. Chu JY, Monteleone JA, Peden VH, Graviss ER, Vernava BS. Anaemia in children and adolescents with hypothyroidism. Clin Pediatr. 1981;20:696-9.

17. Purkait R, Prasad A, Bhadra R, Basu A. Massive pericardial effusion as the only manifestation of primary hypothyroidism. J Cardiovasc Dis Res. 2013;4: 248-50

18. Deng H, Tan T. Advances in the molecular genetics of non-syndromic syndactyly. Curr Genomics. 2015;16:183-93.

19. Kariminejad A, Stollfuß B, Li Y, Bögershausen N, Boss K, Hennekam RC, et al. Severe Cenani-Lenz syndrome caused by loss of LRP4 function. Am J Med Genet. 2013;161A(6):1475-9.

20. Hettiaracchchi D, Bonnard C, Jayawardana SMA, Jin Ng AY, Tohari S, Venkates B, et al. Cenani-Lenz Syndactyly syndrome - a case report of a family with isolated syndactyly. BMC Med Genet. 2018;19:125.

21. JJarbhoua H, Hamamya H, Al-Hadidyb A, Ajlounia K. Cenani-Lenz syndactyly with facial dysmorphism, hypothyroidism, and renal hypoplasia: a case report. Clin Dysmorphol. 2008;17:269-70.

22. Smets $G$, Vankan $Y$, Demeyere A. A female newborn infant with FATCO syndrome variant (fibular hypoplasia, tibial campomelia, oligosyndactyly) - a case report. J Belgian Soc Radiol. 2016;100(1):41-4.

23. Wilcow W, Coulter CP, Schmitz ML. Congenital limb deficiency disorders. Clin Perinatol. 2015;42(2):281-300.
24. Stevens P, Arms D. Postaxial hypoplasia of the lower extremity. J Pediatr Orthop B. 2000;20(2):166-72

25. Hulinsky R, Byrne JBL, Lowichik A, Viskochil DH. Fetus with interstitial del (5)(p13.1p14.2) diagnosed postnatally with Cornelia de Lange syndrome. Am J Med Genet. 2005;137A:336-8.

26. Bosse $\mathrm{K}$, Betz RC, Lee YA, Wienker TF, Reis A, Kleen $\mathrm{H}$, et al. Localization of a gene for syndactyly type a to chromosome 2q34-q36. Am J Hum Genet. 2000;67:492-7.

\section{Publisher's Note}

Springer Nature remains neutral with regard to jurisdictional claims in published maps and institutional affiliations.
Ready to submit your research? Choose BMC and benefit from:

- fast, convenient online submission

- thorough peer review by experienced researchers in your field

- rapid publication on acceptance

- support for research data, including large and complex data types

- gold Open Access which fosters wider collaboration and increased citations

- maximum visibility for your research: over $100 \mathrm{M}$ website views per year

At BMC, research is always in progress.

Learn more biomedcentral.com/submissions 